\title{
AVALIAÇÃO MICROBIOLÓGICA DE HORTALIÇAS E FRUTAS MINIMAMENTE PROCESSADAS COMERCIALIZADAS EM FORTALEZA (CE)
}

\author{
LAURA MARIA BRUNO* \\ ANA AMÉLIA MARTINS DE QUEIROZ** \\ ANA PAULA COLARES DE ANDRADE** \\ NATÁLIA MOURA DE VASCONCELOS** \\ MARIA DE FÁTIMA BORGES***
}

\begin{abstract}
Avaliou-se a qualidade microbiológica de 15 amostras de hortaliças/tubérculos e de 15 amostras de frutas minimamente processadas, comercializadas em Fortaleza (CE). Foram realizadas análises de coliformes fecais e totais, pesquisa de Salmonella sp., contagem total de bolores e leveduras, contagem de Staphylococcus coagulase positiva e contagem total de psicrotróficos. Detectou-se a presença de Salmonella em $66,6 \%$ das amostras de hortaliças/tubérculos e em $26 \%$ das de frutas. Foi verificado que $13,3 \%$ das amostras de hortaliças/ tubérculos apresentaram contagem de coliformes fecais acima do limite estabelecido pela legislação brasileira. Contagens elevadas de coliformes totais, de bolores e leveduras e de psicrotróficos também foram encontradas em ambos os produtos, indicando condições inadequadas de higiene durante o processamento, comprometendo seu armazenamento e sua qualidade microbiológica.
\end{abstract}

PALAVRAS-CHAVE: PRODUTOS MINIMAMENTE PROCESSADOS; COLIFORMES; FUNGOS; Staphylococcus; Salmonella.

\section{INTRODUÇÃO}

O mercado de produtos hortícolas frescos tem crescido de maneira significativa, destacando-se o segmento de produtos lavados,

\footnotetext{
* Engenheira de Alimentos, Doutora em Ciências Biológicas, Pesquisadora da Embrapa Agroindústria Tropical, Fortaleza, CE (e-mail: Imbruno@cnpat.embrapa.br).

Graduandas de Engenharia de Alimentos, Universidade Federal do Ceará, estagiárias da Embrapa Agroindústria Tropical.

Farmacêutica, Doutoranda em Tecnologia de Alimentos, Pesquisadora da Embrapa Agroindústria Tropical.
} 
descascados, cortados ou fatiados, embalados cru e armazenados sob refrigeração, conhecidos como minimamente processados (BERBARI, PASCHOALINO e SILVEIRA, 2001). Outras denominações para esse tipo de produto são: levemente processado, parcialmente processado, processado fresco, cortado fresco ou pré-preparado (CHITARRA, 1998).

O processamento mínimo inclui todas as operações de limpeza, lavagem, seleção, descascamento, corte, embalagem e armazenamento (ROSA e CARVALHO, 2000) que interferem nos fatores físicos, químicos e biológicos responsáveis pela deterioração do produto. Por exemplo, cortes ou danos no tecido da planta promovem liberação de nutrientes e enzimas intracelulares que favorecem a atividade enzimática e a proliferação de microrganismos (FANTUZI, PUSCHMANN e VANETTI, 2004). Além disso, prejudicam a aparência, aceleraram a senescência e a liberação de odores indesejáveis devido à aceleração da respiração e da produção de etileno nos locais cortados (MATTIUZ, DURIGAN e ROSSI JÚNIOR, 2003).

Frutas e hortaliças apresentam microbiota natural que provém do ambiente, sendo influenciada pela estrutura da planta, técnicas de cultivo, transporte e armazenamento (PACHECO et al., 2002; ROSA e CARVALHO, 2000). Conseqüentemente, a microbiota encontrada em produtos minimamente processados é a mesma que ocorre na produção no campo, constituída tipicamente por microrganismos que não são patogênicos para o homem (ZAGORY, 1999). No entanto, mudanças em práticas agronômicas ou de processamento, preservação, embalagem, distribuição e comercialização dos alimentos têm sido responsabilizadas pelo aumento no número de surtos ou infecções causadas por patógenos veiculados por vegetais. Tais alterações incluem o uso de esterco animal que não sofreu compostagem como fertilizante e o uso de esgoto ou de água de irrigação não-tratada, as quais podem contribuir para a contaminação do alimento por patógenos ainda no campo (BEUCHAT, 2002).

A contaminação de produtos minimamente processados ocorre durante as operações de corte e fatiamento, nas quais patógenos presentes na superfície da matéria-prima ou nas mãos dos manipuladores passam para o produto (ROSA e CARVALHO, 2000). Assim, o manuseio sob condições inadequadas de higiene durante o processamento, associado ao aumento dos danos aos tecidos e à higienização insatisfatória dos equipamentos, contribui para a elevação da população microbiana em vegetais. Tal fato aumenta o risco da presença de patógenos e de microrganismos deterioradores nesses produtos (FANTUZI, PUSCHMANN e VANETTI, 2004; VITTI et al., 2004). A refrigeração imprópria durante a 
estocagem também tem sido associada ao aumento de microrganismos aeróbios mesófilos em produtos minimamente processados (BABIC et al., 1996).

Entre os patógenos isolados em produtos minimamente processados podem ser citados: Salmonella, Shigella, Campylobacter, Escherichia coli, Staphylococcus aureus, Clostridium, Bacillus cereus e psicrotróficos como Listeria monocytogenes, Yersinia enterocolitica e Aeromonas hydrophyla (SILVA e GUERRA, 2003; VIEITES et al., 2004).

$\mathrm{O}$ baixo $\mathrm{pH}$ de frutos e hortaliças minimamente processadas e a temperatura de refrigeração favorecem o desenvolvimento de fungos, os quais podem se tornar predominantes no produto (VIEITES et al., 2004). Além de implicados na redução da vida de prateleira do produto podem representar risco à saúde do consumidor, uma vez que alguns fungos patógenos de plantas (Fusarium, Alternaria e Phoma) são também toxigênicos (TOURNAS, 2005).

O objetivo deste trabalho foi avaliar a qualidade microbiológica de frutas e hortaliças minimamente processadas comercializadas na cidade de Fortaleza (CE).

\section{MATERIAL E MÉTODOS}

Trinta amostras de hortaliças, tubérculos e frutas minimamente processados foram adquiridas em supermercados de Fortaleza (CE), no período de janeiro a maio de 2004 , sendo cinco de cada um dos produtos descritos no Quadro 1.

\section{QUADRO 1 - CÓDIGO E DESCRIÇÃO DE HORTALIÇAS, TUBÉRCULOS E FRUTAS MINIMAMENTE PROCESSADOS}

\begin{tabular}{|c|c|c|}
\hline Produto & $\begin{array}{l}\text { Código } \\
\text { da } \\
\text { amostra }\end{array}$ & D escrição \\
\hline Legumescrus & LC & $\begin{array}{l}\text { pedaços descascados de vagem, cenoura, } \\
\text { jerimum, repolho e chuchu crus em embalagem } \\
\text { comercial }\end{array}$ \\
\hline Macaxeira & $\mathrm{MA}$ & $\begin{array}{l}\text { pedaços descascados de macaxeira crua em } \\
\text { embalagem comercial }\end{array}$ \\
\hline $\begin{array}{c}\text { Cenourae repolho } \\
\text { ralados }\end{array}$ & C R & $\begin{array}{l}\text { cenoura e repolho crus, ralados, embalados em } \\
\text { bandeja de isopor, recobertacom filme plástico }\end{array}$ \\
\hline Abacaxi & $A B$ & $\begin{array}{l}\text { descascado, cortado em rodelas, embalado em } \\
\text { bandeja de isopor, recoberta com filme plástico }\end{array}$ \\
\hline Mamão formosa & MF & $\begin{array}{l}\text { descascado, cortado em pedaços, embalado em } \\
\text { bandejade isopor, recoberta com filme plástico }\end{array}$ \\
\hline Salada de frutas & SF & $\begin{array}{l}\text { pedaços descascados de mamão, melão, } \\
\text { manga, uva e laranja, acondicionados em potes } \\
\text { de plástico }\end{array}$ \\
\hline
\end{tabular}


As amostras foram submetidas às análises de coliformes totais $\left(35^{\circ} \mathrm{C}\right) \mathrm{e}$ fecais $\left(45^{\circ} \mathrm{C}\right)$, contagem de psicrotróficos, contagem de bolores e leveduras, contagem de Staphylococcus coagulase positiva e presença de Salmonella sp., segundo metodologias descritas pela APHA (2001) e por SILVA, JUNQUEIRA e SILVEIRA (2001).

\section{RESULTADOS E DISCUSSÃO}

Os resultados das avaliações microbiológicas das hortaliças/tubérculos e frutas minimamente processadas podem ser observados, respectivamente, nas Tabelas 1 e 2 . Em relação a contagem de coliformes totais $\left(35^{\circ} \mathrm{C}\right), 53,3 \%$ das amostras de hortaliças/tubérculos analisadas e $33 \%$ das amostras de frutas apresentaram resultados superiores a $10^{3} \mathrm{NMP} / \mathrm{g}$. BERBARI, PASCHOALINO e SILVEIRA (2001) consideram elevadas as contagens de coliformes totais acima de $10^{3} \mathrm{NMP} / \mathrm{g}$. Tendo em vista que produtos minimamente processados já deveriam ter sofrido algum tipo de assepsia (como lavagem em água corrente, e/ou sanificação), contagens elevadas de coliformes totais podem indicar processamento em condições higiênico-sanitárias insatisfatórias. Contagens elevadas também podem diminuir a vida de prateleira dos produtos e representar riscos para o consumidor, pois se trata de grupo de microrganismos indicadores de contaminação fecal.

\section{TABELA 1 - RESULTADOS DAS ANÁLISES MICROBIOLÓGICAS EM HORTALIÇAS/TUBÉRCULOS MINIMAMENTE PROCESSADOS}

\begin{tabular}{c|c|c|c|c|c|c}
\hline Amostra & \multicolumn{7}{|c}{ Determinação } \\
\cline { 2 - 6 } & $\begin{array}{c}\text { Coliformes } \\
\text { totais } \\
\text { (NMP/g) }\end{array}$ & $\begin{array}{c}\text { Coliformes } \\
\text { fecais } \\
(\mathrm{NMP} / \mathrm{g})\end{array}$ & $\begin{array}{c}\text { Salmonella } \\
\text { sp. } \\
\text { (em } 25 \mathrm{~g})\end{array}$ & $\begin{array}{c}\text { Bolores e } \\
\text { leveduras } \\
\text { (UFC/g) }\end{array}$ & $\begin{array}{c}\text { Staphylococcus } \\
\text { coagulase } \\
\text { positiva } \\
\text { (UFC/g) }\end{array}$ & $\begin{array}{c}\text { Psicrotróficos } \\
\text { (UFC/g) }\end{array}$ \\
\hline LC & $>1100$ & $<3$ & Presença & $3,3 \times 10^{3}$ & $<100$ & $5,6 \times 10^{\prime}$ \\
\hline LC & 240 & 11 & Presença & $6,5 \times 10^{6}$ & $4,1 \times 10^{4}$ & $<100$ \\
\hline LC & $>1100$ & 1100 & Presença & $5 \times 10^{2}$ & $<100$ & $2,6 \times 10^{5}$ \\
\hline LC & 28 & $<3$ & Ausência & $2,2 \times 10^{3}$ & $<100$ & $2,2 \times 10^{3}$ \\
\hline LC & 210 & 93 & Presença & $3,1 \times 10^{3}$ & $<100$ & $6,2 \times 10^{5}$ \\
\hline MA & 11 & 3 & Presença & $5,9 \times 10^{4}$ & $<100$ & $1,4 \times 10^{8}$ \\
\hline MA & 28 & 11 & Presença & $1,3 \times 10^{4}$ & $6,5 \times 10^{3}$ & $<100$ \\
\hline MA & 23 & 3 & Ausência & $8,6 \times 10^{3}$ & $<100$ & $1,4 \times 10^{8}$ \\
\hline MA & $>1100$ & $>1100$ & Ausência & $1,6 \times 10^{3}$ & $<100$ & $6,8 \times 10^{\prime}$ \\
\hline MA & $>1100$ & 21 & Presença & $1,9 \times 10^{5}$ & $<100$ & $<100$ \\
\hline CR & $>1100$ & 23 & Ausência & $1,6 \times 10^{6}$ & $<100$ & $1,8 \times 10^{\prime}$ \\
\hline CR & 11 & 11 & Ausência & $7,6 \times 10^{4}$ & $<100$ & $1,2 \times 10^{\prime}$ \\
\hline CR & $>1100$ & 15 & Presença & $1,6 \times 10^{5}$ & $<100$ & $>6,5 \times 10^{6}$ \\
\hline CR & $>1100$ & 11 & Presença & $4,1 \times 10^{4}$ & $<100$ & $1,9 \times 10^{\prime}$ \\
\hline CR & $>1100$ & $<3$ & Presença & $3,7 \times 10^{6}$ & $<100$ & $2,0 \times 10^{\prime}$ \\
\hline L
\end{tabular}

$\mathrm{LC}=$ Legumes crus.

$M A=$ Macaxeira.

$\mathrm{CR}=$ Cenoura e repolhos ralados. 


\section{TABELA 2 - RESULTADOS DAS ANÁLISES MICROBIOLÓGICAS EM FRUTAS MINIMAMENTE PROCESSADAS}

\begin{tabular}{|c|c|c|c|c|c|c|}
\hline \multirow[t]{2}{*}{ Amostra } & \multicolumn{6}{|c|}{ Determinação } \\
\hline & $\begin{array}{c}\text { Coliformes } \\
\text { totais } \\
\text { (NMP/g) }\end{array}$ & $\begin{array}{l}\text { Coliformes } \\
\text { fecais } \\
\text { (NMP/g) }\end{array}$ & $\begin{array}{c}\text { Salmonella } \\
\text { sp. } \\
\text { (em } 25 \mathrm{~g})\end{array}$ & $\begin{array}{c}\text { Bolores e } \\
\text { leveduras } \\
\text { (UFC/g) }\end{array}$ & $\begin{array}{c}\text { Staphylococcus } \\
\text { coagulase } \\
\text { positiva } \\
\text { (UFC/g) }\end{array}$ & $\begin{array}{l}\text { Psicrotróficos } \\
\text { (UFC/g) }\end{array}$ \\
\hline SF & $>1100$ & 7 & Ausência & $1,8 \times 10^{5}$ & $<100$ & $1,8 \times 10^{4}$ \\
\hline SF & 1100 & 20 & Ausência & $2,1 \times 10^{4}$ & $<100$ & $2,3 \times 10^{5}$ \\
\hline SF & $>1100$ & $<3$ & Presença & $4,8 \times 10^{3}$ & $<100$ & $1,7 \times 10^{5}$ \\
\hline SF & 210 & $<3$ & Ausência & $1,8 \times 10^{5}$ & $<100$ & $1,9 \times 10^{4}$ \\
\hline SF & 240 & $<3$ & Presença & $8,8 \times 10^{3}$ & $<100$ & $<100$ \\
\hline MF & $>1100$ & 75 & Ausência & $2,5 \times 10^{4}$ & $<100$ & $2,5 \times 10^{5}$ \\
\hline MF & $>1100$ & 23 & Ausência & $9 \times 10^{2}$ & $<100$ & $2,9 \times 10^{4}$ \\
\hline MF & 210 & $<3$ & Ausência & $2 \times 10^{5}$ & $<100$ & $2,1 \times 10^{6}$ \\
\hline MF & 39 & $<3$ & Ausência & $6,5 \times 10^{3}$ & $<100$ & $3,4 \times 10^{2}$ \\
\hline MF & 240 & $<3$ & Ausência & $4,4 \times 10^{5}$ & $<100$ & $4,4 \times 10^{5}$ \\
\hline$A B$ & $<3$ & $<3$ & Ausência & $3,6 \times 10^{4}$ & $<100$ & $2 \times 10^{3}$ \\
\hline$A B$ & $<3$ & $<3$ & Presença & $5,6 \times 10^{4}$ & $<100$ & $1,5 \times 10^{3}$ \\
\hline$A B$ & 11 & $<3$ & Ausência & $4 \times 10^{4}$ & $<100$ & $2 \times 10^{4}$ \\
\hline$A B$ & 4 & $<3$ & Presença & $1,9 \times 10^{5}$ & $<100$ & $2,8 \times 10^{2}$ \\
\hline$A B$ & $<3$ & $<3$ & Ausência & $6,5 \times 10^{3}$ & $<100$ & $<100$ \\
\hline
\end{tabular}

$\mathrm{SF}=$ salada de frutas

$\mathrm{MF}=$ mamão formosa.

$\mathrm{AB}=$ Abacaxi.

A RDC n 12, de 02 de janeiro de 2001, da ANVISA (2003) estabelece os seguintes limites para a contagem de coliformes fecais $\left(45^{\circ} \mathrm{C}\right)$ : $10^{2} \mathrm{NMP} / \mathrm{g}$ para hortaliças, $5 \times 10^{2} \mathrm{NMP} / \mathrm{g}$ para frutas e $10^{3} \mathrm{NMP} / \mathrm{g}$ para raízes, tubérculos e similares pertencem à categoria frescos, "in natura", preparados, sanificados, refrigerados ou congelados para consumo direto. A referida legislação exige ausência de Salmonella sp./25 g para todos os produtos mencionados anteriormente.

Verificou-se que 13,3\% das amostras de hortaliças/tubérculos apresentaram contagem de coliformes fecais acima do padrão recomendado pela legislação vigente. Dessas, $66,6 \%$ foram positivas para presença de Salmonella sp. e consideradas impróprias para o consumo. Embora todas as amostras de fruta tenham atendido ao padrão para contagem de coliformes fecais, $26,6 \%$ dessas foram consideradas inadequadas para consumo devido a presença de Salmonella sp. 
Provavelmente as amostras de legumes e macaxeira, durante o seu preparo, sofrerão redução na carga microbiana pela ação do calor, minimizando os riscos associados ao seu consumo. Das amostras positivas para Salmonella sp., três eram de cenoura e repolho ralados, duas de saladas de frutas e duas de abacaxi. Tratando-se de produtos para serem consumidos crus, tal contaminação representa grande risco à saúde humana. REIS et al. (2003) analisaram minimilho minimamente processado, FERREIRA et al. (2003), estudaram legumes e verduras minimamente processados e congelados, enquanto PEREIRA, PEREIRA e MIYA (2004) avaliaram manga palmer minimamente processada. Observaram que em relação a coliformes fecais, todas as amostras analisadas enquadraram-se nos padrões da legislação brasileira. Além da análise de coliformes fecais, FERREIRA et al. (2003) pesquisaram a presença de Salmonella sp. em legumes e verduras minimamente processadas e congeladas, mas não detectaram sua presença nas amostras analisadas.

Entre os vegetais implicados em surtos de salmonelose pode-se destacar a melancia, o melão, o tomate e brotos de alfafa (BEUCHAT, 2002). Também tem sido relatada a ocorrência do crescimento de E. coli O157:H7 e Salmonella em vários tipos de produtos como maçãs minimamente processadas, sidra de maçã e produtos de tomate e de laranja sem pele (BHAGWAT, SAFTNER e ABBOT, 2004). A adaptação de microrganismos patogênicos às condições de estresse ambiental, como a sobrevivência em pH muito ácido em alimentos e no estômago contribui para essa situação (BEUCHAT, 2002, BHAGWAT, SAFTNER e ABBOT, 2004). Além disso, o uso de sanificantes na água de lavagem ao mesmo tempo em que reduz a carga microbiana inicial de 1-2 ciclos logarítmicos pode favorecer o crescimento do patógeno pela diminuição da microbiota competitiva (ZAGORY, 1999). A falta de eficácia do sanificante usado para descontaminar a superfície de frutas e vegetais crus tem sido amplamente atribuída à inabilidade dos componentes ativos da solução em inibir ou inativar as células microbianas (BECHAUT, 2002). Outros fatores, como a concentração do sanificante e o tempo de contato com a superfície a ser desinfetada, também contribuem para a eficiência ou não do processo de limpeza e sanitização (RÊGO e FARO, 1999). SILVA e GUERRA (2003) avaliaram as condições de produção de frutos minimamente processados numa loja da rede de supermercados de Recife (PE). Observaram que o conteúdo de cloro utilizado na água de lavagem dos frutos estava aquém do recomendado pela legislação, alertando para a necessidade da adoção de Boas Práticas de Fabricação no processamento de alimentos. 
A contagem total de bolores e leveduras variou da ordem de $10^{2}$ a $10^{6} \mathrm{UFC} / \mathrm{g}$ (Tabela 1 ) para as hortaliças minimamente processadas e de $10^{2}$ a $10^{5} \mathrm{UFC} / g$ para frutas minimamente processadas (Tabela 2). BERBARI, PASCHOALINO e SILVEIRA (2001) relataram que a população de bolores e leveduras em alface americana minimamente processada atingiu a ordem de $10^{3} \mathrm{UFC} / \mathrm{g}$ no final de nove dias de armazenamento a $2^{\circ} \mathrm{C}$. PEREIRA, PEREIRA e MIYA (2004) encontraram em manga palmer minimamente processada contagens de bolores e leveduras variando de $10^{3}$ a $10^{6} \mathrm{UFC} / \mathrm{g}$, resultado considerado elevado. VIEITES et al. (2004) também observaram variação na população de bolores e leveduras entre $10^{2}$ e $10^{4} \mathrm{UFC} / \mathrm{g}$ em mamão minimamente processado submetido a diferentes doses de irradiação. WADE et al. (2003) alertam para o fato de que associações metabióticas entre fungos e bactérias que podem causar doenças ao homem são de interesse de saúde pública. $O$ desenvolvimento de fungos pode provocar aumento do $\mathrm{pH}$ de produtos vegetais ácidos (como, por exemplo, tomates e seus derivados) para valores de $\mathrm{pH}$ favoráveis ao crescimento de bactérias patogênicas (tais como Salmonella e C. botulinum), podendo desencadear surtos de toxinfecção alimentar. Assim, mais uma vez ressalta-se a necessidade da adoção de Boas Práticas de Fabricação durante a elaboração de minimamente processados.

Apenas duas amostras de hortaliças/tubérculos apresentaram contagens de Staphylococcus coagulase positiva acima de $10^{2} \mathrm{UFC} / \mathrm{g}$, sendo uma de legumes e outra de macaxeira (Tabela 1). FERREIRA et al. (2003) pesquisaram a presença de Staphylococcus em legumes e verduras minimamente processadas e congeladas comercializadas em São Luís (MA). Encontraram contagens da ordem de $10^{2} \mathrm{UFC} / \mathrm{g}$ em $15 \%$ das amostras. A detecção de Staphylococcus em alimentos está relacionada com manipulação inadequada durante o processamento. As características das amostras analisadas neste trabalho, sobretudo em relação a acidez, podem contribuir para a não-proliferação desse microrganismo.

A contagem de microrganismos psicrotróficos mostrou-se superior a $10^{5} \mathrm{UFC} / \mathrm{g}$ em 73,3\% das amostras de hortaliças/tubérculos (Tabela 1) e em 33,3\% das de frutas (Tabela 2) minimamente processadas. A maior contagem microbiana detectada em hortaliças/tubérculos, provavelmente, está relacionada com suas características físico-químicas que devem favorecer o crescimento microbiano. FANTUZZI, PUSCHMANN e VANETTI (2004) encontraram contagem inicial de microrganismos psicrotróficos da ordem de $10^{4} \mathrm{UFC} / \mathrm{g}$ em repolho minimamente processado, a qual 
não variou durante 20 dias de estocagem em temperaturas entre 1 e $5^{\circ} \mathrm{C}$. VITTI et al. (2004), trabalhando com beterrabas minimamente processadas, observaram que a contagem total de bactérias psicrotróficas variou de $10^{2}$ para $10^{4} \mathrm{UFC} / \mathrm{g}$ num período de 10 dias em temperatura de armazenamento de $5^{\circ} \mathrm{C}$. De acordo com VITTI et al. (2004) tem sido preconizado que alimentos com contagens microbianas de psicrotróficos acima de $10^{5} \mathrm{UFC} / \mathrm{g}$ podem ser considerados impróprios para consumo humano pela perda do valor nutricional, alterações organolépticas e riscos de contaminação. O risco de contaminação por patógenos psicrotróficos está associado à presença de microrganismos como L. monocytogenes. Vale ainda salientar que muitos microrganismos deterioradores são psicrotróficos e a presença elevada desse grupo de microrganismos pode contribuir para redução da vida de prateleira de minimamente processados e indicar também que as operações de limpeza e sanitização empregadas durante o processamento não foram eficientes.

\title{
4 CONCLUSÃO
}

Verificou-se a presença de Salmonella sp. em $66,6 \%$ das amostras de hortaliças/tubérculos e $26 \%$ das amostras de frutas. A detecção de coliformes fecais acima do limite permitido pela legislação brasileira em $13,3 \%$ das amostras de hortaliças/tubérculos e as elevadas contagens microbianas de coliformes totais e de psicrotróficos em ambas amostras indicam que o processamento pode estar sendo realizado em condições higiênico-sanitárias insatisfatórias. Sugere-se a adoção de Boas Práticas de Fabricação durante o processamento mínimo para garantir a segurança microbiológica dos produtos.

\begin{abstract}
MICROBIOLOGICAL EVALUATION OF VEGETABLES AND FRUITS MINIMALLY PROCESSED MARKETED IN FORTALEZA (CE)

The microbiological quality of 15 vegetables and 15 fruits minimally processed samples marketed in Fortaleza - CE (Brazil) was evaluated. The following analyses were carried out: total and fecal coliforms, Salmonella sp., total yeasts and moulds count, coagulase positive Staphylococcus count and total psychrotrophics count. Salmonella was detected in $66.6 \%$ of vegetable samples and $26 \%$ of fruit samples. Fecal coliforms count higher than legislation limit, it was verified in $13.3 \%$ of vegetable samples. High counts of total coliforms, yeasts and moulds and psychrotrophics were also found on both products, showing inadequate hygiene conditions during manufacturing, affecting storage and microbiological quality of minimally processed fruits and vegetables.
\end{abstract}

KEY-WORDS: MINIMALLY PROCESSED PRODUCTS; COLIFORMS; MOULDS; Staphylococcus, Salmonella. 


\section{REFERÊNCIAS}

1 ANVISA. Agência Nacional de Vigilância Sanitária. Resolução RDC n. 12 de 02 de janeiro de 2001 on line. Regulamento técnico sobre padrões microbiológicos para alimentos. Disponível em: <http://e-legis.bvs.br> Acesso em: 03 de fevereiro de 2003.

APHA. American Public Health Association. Compendium of the methods for the microbiological examination of foods. $4^{\text {th }}$. Washington, 2001. $676 \mathrm{p}$.

BABIC, I.; ROY, S.; WATADA, A.E.; WERGIN, W.P. Changes in microbial populations on fresh cut spinach. International Journal of Food Microbiology, v.31, n. 1-3, p. 107-119, Aug. 1996.

BERBARI, S.A.G.; PASCHOALINO, J.E.; SILVEIRA, N.F.A. Efeito do cloro na água de lavagem para desinfecção de alface minimamente processada. Ciência e Tecnologia de Alimentos, v.21, n.2, p. 197-201, maio/ago. 2001.

BEUCHAT, L.R. Ecological factors influencing survival and growth of human pathogens on row fruits and vegetables. Microbes and Infection, v. 4, n.4, p. 413-423, apr. 2002.

BHAGWAT. A.A.; SAFTNER, R.A.; ABBOT, J.A. Evaluation of wash treatments for survival of foodborne pathogens and maintenance of quality characteristics of fresh-cut apple slices. Food Microbiology, v. 21, n. 3, p. 319-326, Jun. 2004.

CHITARRA, M.I.F. Processamento mínimo de frutos e hortaliças. Viçosa: Centro de Produções Técnicas, 1998. 88 p.

8 FANTUZZI, E.; PUSCHMANN, R.; VANETTI, M.C.D. Microbiota contaminante em repolho minimamente processado. Ciência e Tecnologia de Alimentos, v.24, n.2, p. 207-211, abr./jun. 2004.

9 FERREIRA, M.G.A.B.; BAYMA, A.B.; MARTINS, A.G.L.A.; GARCIAS JÚNIOR, A.V.; MARINHO, S.C. Aspectos higiênico-sanitários de legumes e verduras minimamente processados e congelados. Higiene Alimentar, v. 17, n. 106, p. 49-55, mar. 2003.

MATTIUZ, B.; DURIGAN, J.F.; ROSSI JÚNIOR, O.D. Processamento mínimo em goiabas 'paluma' e 'pedro sato' 2. Avaliação química, sensorial e microbiológica. Ciência e Tecnologia de Alimentos, v. 23, n. 3, p. 409413, set./dez. 2003.

PACHECO, M.A.S.R.; FONSECA, Y.S.K.; DIAS, H.G.G.; CÂNDIDO, V.L.P.; GOMES, A.H.S.; ARMELIN, I.M.; BERNARDES, R. Condições higiênicosanitárias de verduras e legumes comercializados no Ceagesp de SorocabaSP. Higiene Alimentar, v. 16, n. 101, p. 50-55, out. 2002.

PEREIRA, K.S.; PEREIRA, J.L.; MIYA, N.T.N. Análises microbiológicas de manga, 
cultivar Palmer, congelada e minimamente processada. Higiene Alimentar, v. 18, n. 119, p. 47-50, abr. 2004.

REGO, J.S.; FARO, Z.P. Manual de limpeza e desinfecção para unidades produtoras de refeições. São Paulo: Varela, 1999. 64 p.

14 REIS, K.C.; PEREIRA, J.; VALLE, R.H.P.; NERY, F.C. Avaliação da qualidade microbiológica de minimilho (Zea mays) minimamente processado. Higiene Alimentar, v. 17, n. 110, p. 66-68. jul. 2003.

ROSA, O.O.; CARVALHO, E.P. Características microbiológicas de frutos e hortaliças minimamente processados. Boletim da SBCTA. v. 34, n. 2, p. 8492, jul/dez. 2000.

SILVA, M.Z.T.; GUERRA, N.B. Avaliação das condições de frutos minimamente processados. Higiene Alimentar, v. 17, n. 111, p. 29-36, ago. 2003.

SILVA, N.; JUNQUEIRA, V.C.A.; SILVEIRA, N.F.A. Manual de métodos de análise microbiológica de alimentos. São Paulo: Varela, 2001. 317 p.

18 TOURNAS, V.H. Moulds and yeasts in fresh and minimally processed vegetables, and sprouts. International Journal of Food Microbiology, v.99, n. 1, p. 71-77, Mar. 2005.

19 VIEITES, R.L.; EVANGELISTA, R.M.; CAMPOS, A.J.; MOREIRA, G.C. Avaliação da contaminação microbiana do mamão minimamente processado e irradiado. Higiene Alimentar, v 18, n. 118, p. 65-70, mar. 2004.

20 VITTI, M.C.D.; KLUGE, R.A.; GALLO, C.R.; SCHIAVINATO, M.A.; MORETTI, C.L.; JACOMINO, A.P. Aspectos fisiológicos e microbiológicos de beterrabas minimamente processadas. Pesquisa Agropecuária Brasileira, v.39, n.10, p. 1027-1032, out. 2004.

21 WADE, W.N.; VASDINNYEI, R.; DEAK, T.; BEAUCHAT, L.R. Proteolytic yeasts isolated from raw, ripe tomatoes and metabiotic association of Geotrichum candidum with Salmonella. International Journal of Food Microbiology, v.86, n. 1-2, p. 101-111, Sept. 2003.

22 ZAGORY, D. Effects of post-processing handling and packaging on microbial populations. Postharvest Biology and Technology, v. 15, n. 3, p. 313321, Mar. 1999. 